\title{
Correction to: Multilevel particle filters for Lévy-driven stochastic differential equations
}

\author{
Ajay Jasra ${ }^{1} \cdot$ Kody J. H. Law ${ }^{2,3} \cdot$ Prince Peprah Osei $^{1}$ \\ Published online: 30 November 2018 \\ (C) The Author(s) 2018

\section{Correction to: Statistics and Computing https://doi.org/10.1007/s11222-018-9837-z}

The article Multilevel particle filters for Lévy-driven stochastic differential equations, written by Ajay Jasra, Kody J. H. Law, Prince Peprah Osei, was originally published electronically on the publisher's Internet portal (currently SpringerLink) on 20 October 2018 without open access.

With the author(s)' decision to opt for open choice, the copyright of the article is changed on 25 November 2018 to (C) The Author(s) 2018 and the article is forthwith distributed under the terms of the Creative Commons Attribution 4.0 International License (http://creativecommons.org/licenses/ by/4.0/), which permits use, duplication, adaptation, distribution and reproduction in any medium or format, as long as you give appropriate credit to the original author(s) and the source, provide a link to the Creative Commons license and indicate whether changes were made.

The original article was corrected.

Open Access This article is distributed under the terms of the Creative Commons Attribution-NonCommercial 4.0 International License (http://creativecommons.org/licenses/by/4.0/), which permits any noncommercial use, distribution, and reproduction in any medium, provided you give appropriate credit to the original author(s) and the source, provide a link to the Creative Commons license, and indicate if changes were made.
The original article can be found online at https://doi.org/10.1007/ s11222-018-9837-z.

Kody J. H. Law

kody.law@manchester.ac.uk

1 Department of Statistics and Applied Probability, National University of Singapore, Singapore 117546, Singapore

2 School of Mathematics, University of Manchester, Manchester, UK

3 Computer Science and Mathematics Division, Oak Ridge National Laboratory Oak Ridge, Oak Ridge, TN 37831, USA 